NASA Technical Memorandum 89864

$$
\begin{aligned}
& \text { NASA-TM--89864 } \\
& \text { Conf-870804--55 }
\end{aligned}
$$

\title{
Coaxial Tube Array Space Transmission Line Characterization
}

Colleen A. Switzer and David J. Bents

Lewis Research Center

Cleveland, Ohio

Prepared for the

22nd Intersociety Energy Conversion Engineering Conference cosponsored by the AIAA, ANS, ASME, SAE, IEEE, ACS, and AIChE Philadelphia, Pennsylvania, August 10-14, 1987

\section{nos}

\section{MASTER}




\section{DISCLAIMER}

This report was prepared as an account of work sponsored by an agency of the United States Government. Neither the United States Government nor any agency Thereof, nor any of their employees, makes any warranty, express or implied, or assumes any legal liability or responsibility for the accuracy, completeness, or usefulness of any information, apparatus, product, or process disclosed, or represents that its use would not infringe privately owned rights. Reference herein to any specific commercial product, process, or service by trade name, trademark, manufacturer, or otherwise does not necessarily constitute or imply its endorsement, recommendation, or favoring by the United States Government or any agency thereof. The views and opinions of authors expressed herein do not necessarily state or reflect those of the United States Government or any agency thereof. 


\section{DISCLAIMER}

Portions of this document may be illegible in electronic image products. Images are produced from the best available original document. 


\section{DISCLAIMER}

This report was prepared as an account of work sponsored by an agency of the United States Government. Neither the United States Government nor any agency thereof, nor any of their employees, makes any warranty, express or implied, or assumes any legal liability or responsibility for the accuracy, completeness, or usefulness of any information, apparatus, product, or process disclosed, or represents that its use would not infringe privately owned rights. Refer. ence herein to any specific commercial product, process, or service by trade name, trademark, manufacturer, or otherwise does not necessarily constitute or imply its endorsement, recommendation, or favoring by the United States Government or any agency thereof. The views and opinions of authors expressed herein do not necessarily state or reflect those of the United States Government or any agency thereof.

The Goverment reserves for itself and others acting on its behalf a royalty free, nonexclusive, irrevocable, world-wide license for govermental purposes to publish, distribute, translate, duplicate, exhibit, and perform any such data copyrighted by the contractor. 
Colleen A. Switzer and David J. Bents

National Aeronautics and Space Administration

Lewis Research Center

Cleveland, Ohio 44135

\section{Abstract}

The coaxial tube array tether/transmission line used to connect an SP-700 nuclear power system to the space station was characterized over the range of reactor-to platform separation distances of 1 to $10 \mathrm{~km}$. Characterization was done with respect to array performance, physical dimensions, and masses. Using a fixed design procedure, a family of designs were generated for the same power level ( $300 \mathrm{kWe}$ ), power loss ( 1.5 percent), and meteoroid survival probability ( 99.5 percent over $10 \mathrm{yr}$ ). To differentiate between vacuum insulated and gas insulated lines, two different maximum values of the $E$ field were considered: $20 \mathrm{kV} / \mathrm{cm}$ (appropriate to vacuum insulation) and $50 \mathrm{kV} / \mathrm{cm}$ (compressed SF6). Core conductor, tube, bumper, standoff, spacer and bumper support dimensions, and masses were also calculated. The results of the characterization show mainly how transmission line size and mass scale with reactor-to-platform separation distance.

\section{Discussion}

The space power transmission line is the element used to connect SP-100 to a space station (Fig. 1) where the combined spacecraft (platform, transmission line, and remote power system) travels as a tether-connected constellation in gravity gradient stabilized orbit. The power system occupies the superorbital position 1 to $10 \mathrm{~km}$ above the platform. The transmission line mechanically connects SP-100 to the platform and retains it in its remote superorbital position, conveys electrical power, and provides a reactorplatform separation such that radiation levels in the platform vicinity are reduced from instrument safe to man-safe levels.

This transmission line isolates the nuclear power source, but carries the electrical power it produces to users aboard the platform. Key requirements are the ability to convey power with minimal loss across the distance separating the space platform from the $S P-100$, and to perform reliably for $10 \mathrm{yr}$ in the meteoroid environment of low earth orbit. Over the range of reactorto-platform separation distances considered ( 1 to $10 \mathrm{~km}$ ), voltages on the order of several kilovolts are required. Due to the space plasma and its interaction with the spacecraft, however, conventional transmission means such as cables are not viable. This transmission line must be much different in order to isolate the high voltage power transmission from spacecraft/plasma interactions. It is therefore important to consider its construction, the methodology and constraints governing its dimensions.

The coaxial tube array, shown in Fig. 2 , consists of individual tube assemblies enclosed by a common cylindrical meteoroid bumper. Multiple tube assemblies provide redundancy which results in overall system mass reductions.?
Each tube assembly is made up of a solid rod, or core, which is located concentrically inside a jacket tube. Each coaxial tube assembly in the array forms an independent transmission circuit (Fig. 3). Cores are energized at transmission voltage and carry power from the source to the spacecraft. The jacket tube serves as a ground return and provides gaussian isolation of the power system high voltage (inside the tethered spacecraft) from spacecraft/plasma interactions outside.

Array dimensions are governed primarily by transmission voltage (determined by allowable line losses) and by the level of meteoroid survival probability desired. Voltage isolation is accomplished by the coaxial gap between the core and jacket. Standoff capability of this gap depends on the maximum voltage gradient, or $E$ field, which is related to the coaxial parameters by:

$$
E=\frac{v}{r \ln \left(\frac{r_{2}}{r_{1}}\right)}
$$

where

$r$ the radius from the assembly center to a specified point within the annular gap

$r_{1}$ core radius

$r_{2}$ jacket tube inner radius

$\checkmark$ potential between core and jacket

The maximum field that must be withstood obviousiy occurs at the surface of the core

$$
E \mid r=r_{1}=\frac{v}{r_{2}} * \frac{1}{\left(\frac{r_{1}}{r_{2}}\right) \ln \left(\frac{r_{2}}{r_{1}}\right)}
$$

This field then possesses a minimum value when $\ln \left(r_{2} / r_{1}\right)=1$ which relates $r_{2}$ to $r_{1}$. The thickness of the tube is determined from the requirement (current continuity) that the core and jacket cross sections be equal. Cross section is a function of power, voltage, acceptable transmission loss, conductor materials properties, and meteoroid penetration resistance. If a jacket tube is punctured by meteoroids it is permanentiy disabled; therefore it must have sufficient wall thickness for penetration resistance as well as electrical conductivity.

The bumper is a sacrifictal wall which reduces the possibility of tube penetration. This thin wall serves to break up and disperse the incoming meteorold into a cloud of molten droplets and smaller fragments which then impact the tube wall over a wide area instead of a single point. Penetration resistance can be increased 
by either thickening the bumper wall or increasing the gap between the bumper and the tube. Redundant tubes are used to give the transmission line a larger chance of surviving a hit. If three tubes are used, two tubes could be hit over the 10 years and the transmission line can still deliver power.

The designer's task is to meet the conflicting requirements with minimum mass. Due to the geometric relationship previously stated, tube assembly dimensions and characteristics can be expressed as functions of the jacket wall thickness onty. This allows straightforward comparison to be made between electrical transmission requirements versus meteoroid survival probability. The design process typically begins by choosing the highest $E$ field, or voltage gradient, that can be allowed within a tube assembly, then calculating the dimensional parameters (tube size, area at risk) and the electrical parameters (voltage, round trip resistance, dc line loss) as a function of wall thickness.

A computer program was developed to facilitate the design process and provide characterization. For a given allowable gradient, line length, and power per tube the program calculated line voltage, percent power loss, and area at risk for a range of wall thicknesses. From this array of choices a design could be selected that gave a reasonable round trip percent power loss, mass per tube, and small surface area at risk.

The design process continues with meteoroid survival considerations. A survival probability of 99.5 percent would be needed if the array used only one tube. But if three redundant tubes are used, there only needs to be an 85 percent survival probability on an individual tube for a 99.5 percent probability that at least one out of the three lines will survive.

The mass of the largest meteoroid which the tube must resist during the $10 \mathrm{yr}$ of expected life needs to be found next. The mass of the meteoroid is found by finding $N_{t}$, the number of particles of mass $m$ or greater per square meter per second. This is done using the following equation with $p$ being the probability needed per tube.

$P(n$ or fewer strikes $)=\sum_{r=0}^{r=n} \frac{e^{-N_{t} A T}\left(N_{t} A T\right)^{r}}{r !}$ where

A area at risk

$T$ time in seconds

$n$ is zero in this case since no strikes are a) lowed

Once $\mathrm{N}_{t}$ is found then the mass of the largest possible meteoroid can be found using

$$
\log N_{t}=-14.37-1.213 \log m
$$

(does not account for space debris)

This is the largest meteoroid the array would be expected to encounter during its life, and the largest one it must resist. Penetration resistance is designed into the array by choosing bumper thickness and gap according to the following empirical method: the mass of the meteoroid is converted to an equivalent aluminum sphere of diameter $D$. A graph is entered next, which relates penetration resistance of a two sheet aluminum barrier to the bumper and tube wall construction of the array. The graph (Fig. 4) is an experimentally determined penetration relation for aluminum projectiles fired into aluminum sheets ( $\mathrm{Fig} .47)^{2}$ and it is used to determine the thickness of the bumper wall and the minimum bumper to wall separation. The first sheet of aluminum, $T 1$, is the bumper, the space, SI, between the two sheets is the bumper separtion gap, and the second sheet, $T 2$, is equivalent to the tube wall. To minimize the weight of the tube array it is best to stay as close as possible to the diagonal line for minimum $T 1 / D+T 2 / D$. once the bumper thickness and diameter have been established, the mass of the array itself can be calculated depending on how many redundant coaxial tubes are used.

Further characterization of the transmission line considers the dielectric spacers, sleeves, and bumper spacers ( $\mathrm{FIg} .5)$. The purpose of the dielectric spacers are two-fold. The first is to help prevent arcing between the core and the jacket wall and secondly to keep the core centered in the jacket. A spring steel sleeve is used between the two rows of beads to hold them tight against the wall and core. There is one spring steel sleeve for every six beads. The dielectric spacers are made of glass and their length is twice their diameter. The spring steel sleeve is twice the length of the dielectric spacers; for the $300 \mathrm{kWe}$ design it is $0.254 \mathrm{~mm}$ thick. The bumper spacers keep the three coaxial tubes in proper position. The bumper spacers are $0.72 \mathrm{~mm}$ thick; they are made from aluminum $6061-T 6$.

Longitudinal spacing for dielectric spacer and bumper spacers is found by looking at a worst case bend for the tether $\left(90^{\circ}\right)$. The dielectric spacer interval is calculated by finding the radius of curvature, and spacing the dielectric spacers just far enough apart so that the core does not deflect more than one-third the minimum gap distance. The bumper spacers interval is found the same way except the coaxial tubes can deflect half the distance between the bumper and the tubes.

The mass added onto the tether from the spacers and sleeves is negligible compared to the mass of the tether itself. The computer program developed to perform these calculations outputs all needed dimensions, numbers of items, and masses of the spacers and sleeves.

\section{Results and Summary}

The design procedure was exercised over a range of distances from 1 to $10 \mathrm{~km}$, for a 99.5 percent probability of one out of the three tubes surviving $10 \mathrm{yr}$. All designs have a $300 \mathrm{~kW}$ power level and a nominal 1.5 percent power loss. Two values of the voltage gradient were considered; $20 \mathrm{kV} / \mathrm{cm}$, appropriate for the vacuum insulation, and $50 \mathrm{kV} / \mathrm{cm}$, comparable to pressurized SF6. Table I compares the mass, tube diameters, area at risk, and the amount of spacers needed for the coaxial array at these gradients over a 
variety of separation distances from 1 to $10 \mathrm{~km}$. Figure 6 compares the cross section of two $10 \mathrm{~km}$ tether/transmission lines, notice the difference in tube size as the gradient is changed. Figure 7 compares a $1 \mathrm{~km}$ and $10 \mathrm{~km}$ tether at $50 \mathrm{kV} / \mathrm{cm}$. of most interest to the system designer is a summarization of mass versus separation distance which is presented in Fig. 8 .

A definite difference can be seen between the 20 and the $50 \mathrm{kV} / \mathrm{cm}$ line. The bumper diameter does not change very much between the two gradients, but the tube diameter size of the $50 \mathrm{kV} / \mathrm{cm}$ line is reduced to about two-thirds the diameter of the $20 \mathrm{kV} / \mathrm{cm}$ line. Using the higher voltage gradient the mass of the line was roughiy cut in half. Longer lines are heavier per unit length; using the higher voltage gradient allows for lighter Tines.

\section{References}

1. D.J. Bents: "Tethered Nuclear Power for the Space Station." NASA TM-87023, 1985 IECEC, Míami.

2. J.F. Lundeberg, P.H. Stern, and R.J. Bristow: "Meteoroid Protection for Spacecraft Structures." Boeing Co., Seattle, WA, D2-24056, 0ct. 1985. (NASA CR-54201.)

TABLE I. - COAXIAL TUBE ARRAY CHARACTERISTICS AT SELECTED SEPARATION DISTANCES

\begin{tabular}{|c|c|c|c|c|c|c|c|c|c|c|}
\hline \multirow[b]{2}{*}{ Length, $\mathrm{km}$} & \multicolumn{5}{|c|}{$20 \mathrm{kV} / \mathrm{cm}$} & \multicolumn{5}{|c|}{$50 \mathrm{kV} / \mathrm{cm}$} \\
\hline & 7 & 3 & 5 & 8 & 10 & 1 & 3 & 5 & 8 & 10 \\
\hline Assembly mass, $\mathrm{kg}$ & 364 & 1937 & 4257 & 8751 & 12783 & 182 & 969 & 2187 & 4743 & 6530 \\
\hline Tube od, mm & 13.7 & 17.7 & 20.1 & 22.5 & 24.1 & 8.9 & 11.3 & 12.9 & 14.5 & 15.3 \\
\hline Wall thickness, mm & 0.84 & 1.1 & 1.24 & 1.4 & 1.5 & 0.54 & 0.7 & 0.8 & 0.9 & 0.94 \\
\hline Bumper diameter, mm & 80 & 117 & 144.5 & 176.5 & 200 & 83.5 & 123 & 151 & 192.6 & 218.6 \\
\hline Bumper thickness, mm & 0.118 & 0.16 & 0.19 & 0.204 & 0.22 & .09 & 0.12 & 0.14 & 0.163 & 0.16 \\
\hline Area at risk, $\mathrm{m}^{2}$ & 43 & 167 & 316 & 566 & 758 & 28 & 106 & 202 & 364 & 480 \\
\hline volts, $\mathrm{kV}$ & 4.7 & 6.1 & 7 & 7.8 & 8.4 & 7.7 & 9.8 & 11.2 & 12.6 & 13.3 \\
\hline Number of beads & 1619 & 2491 & 3051 & 3647 & 3939 & 2012 & 3131 & 3785 & 4549 & 5158 \\
\hline Number of sleeves & 269 & 415 & 508 & 607 & 656 & 335 & 521 & 630 & 758 & 859 \\
\hline Number of bumper spacers & 151 & 201 & 225 & 248 & 255 & 120 & 166 & 190 & 208 & 216 \\
\hline $\begin{array}{l}\text { beads, m } \\
\text { Distance between bumper }\end{array}$ & 3.7 & 7.2 & 9.8 & 13.2 & 15.2 & 3.0 & 5.75 & 7.93 & 10.6 & 11.6 \\
\hline spacers, m & 6.6 & 14.9 & 22.2 & 32.2 & 39.1 & 8.3 & 18.0 & 26.2 & 38.4 & 46.1 \\
\hline
\end{tabular}




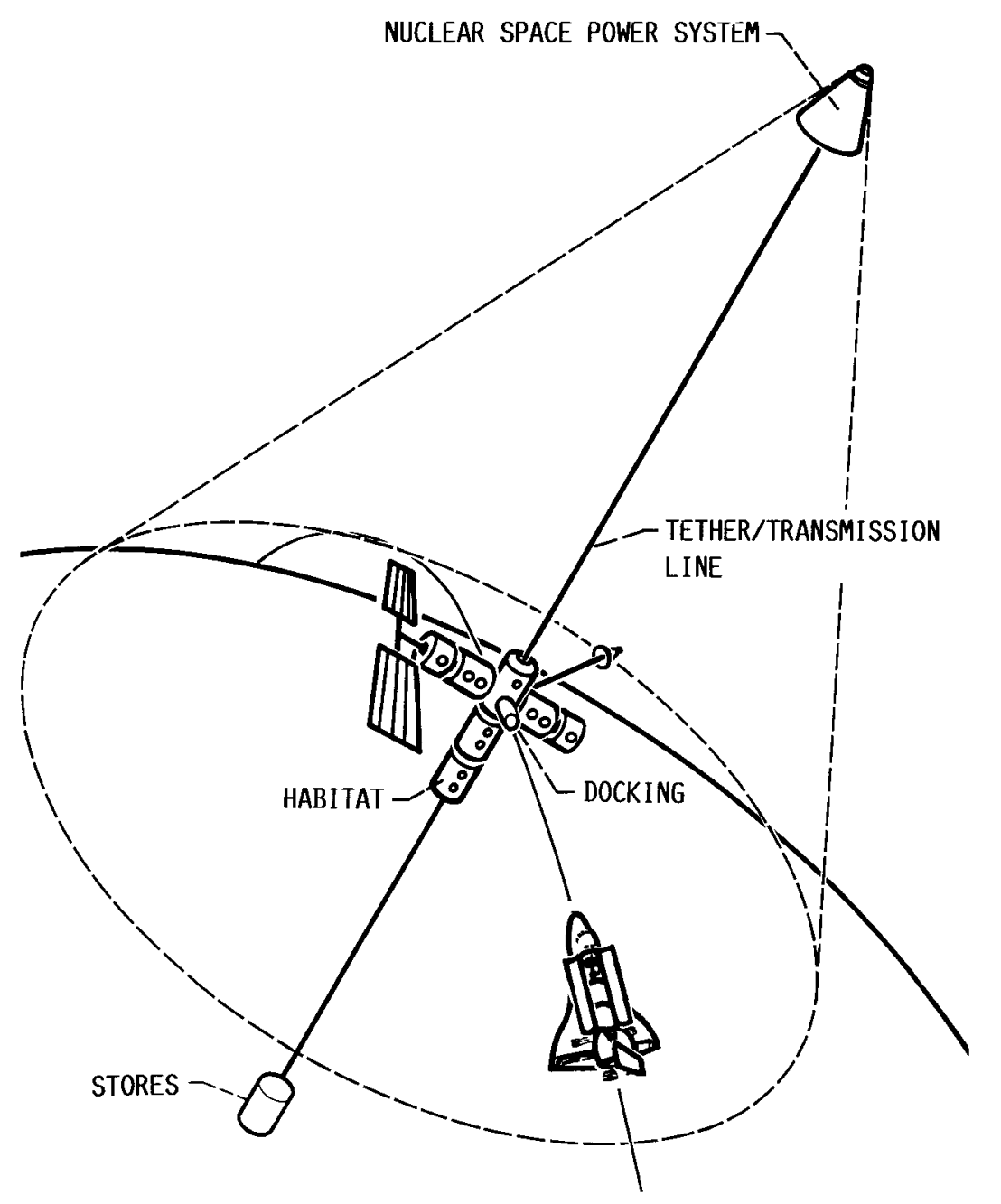

FIGURE 1. - SPACE STATION POWERED BY TETHERED NUCLEAR SYSTEM. 


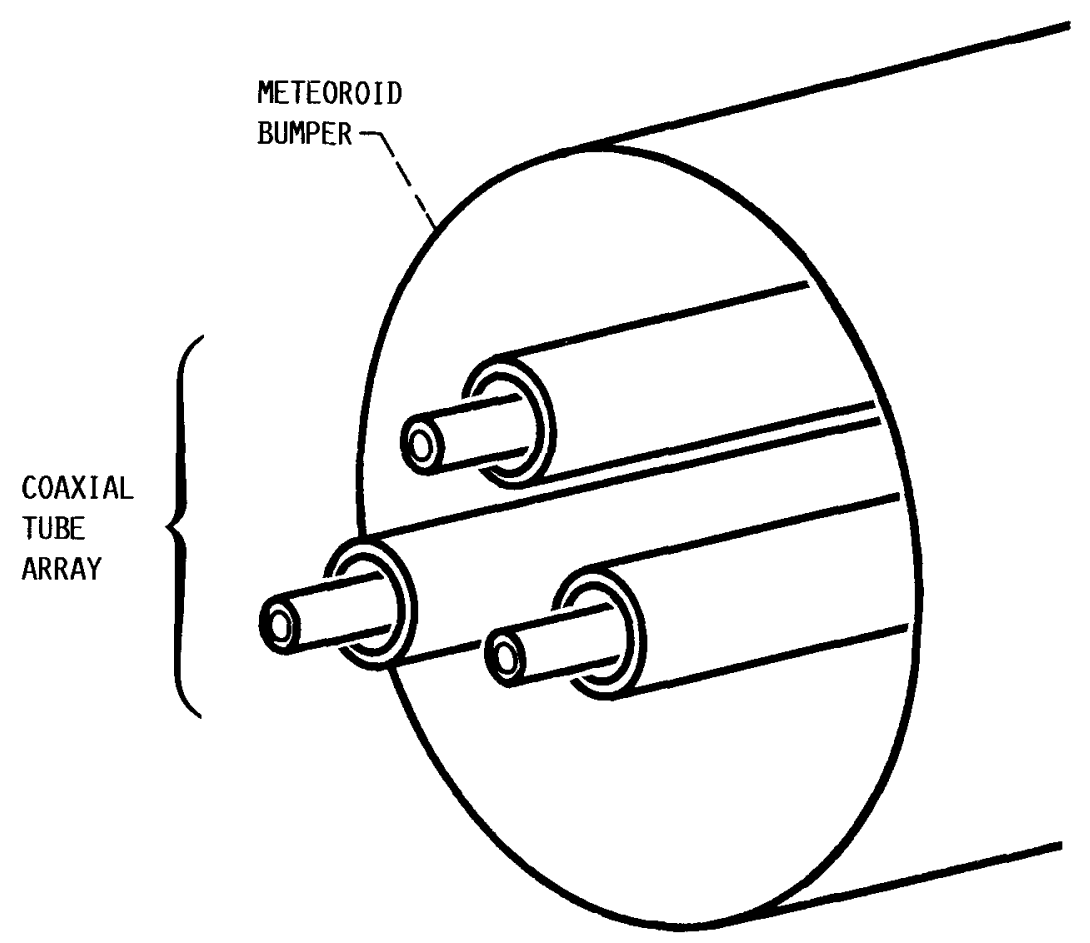

FIGURE 2. - SPACE TRANSMISSION LINE.

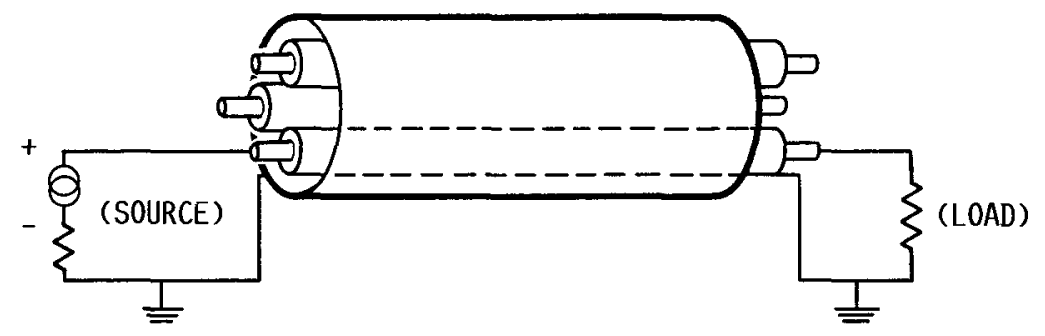

POWER SYSTEM

SPACE PLATFORM

FIGURE 3. - SOURCE TO LOAD CONNECTION WITH COAXIAL TUBES. ( 3 TUBE ARRAY, 1 OUT OF 3 CIRCUITS SHOWN.) 


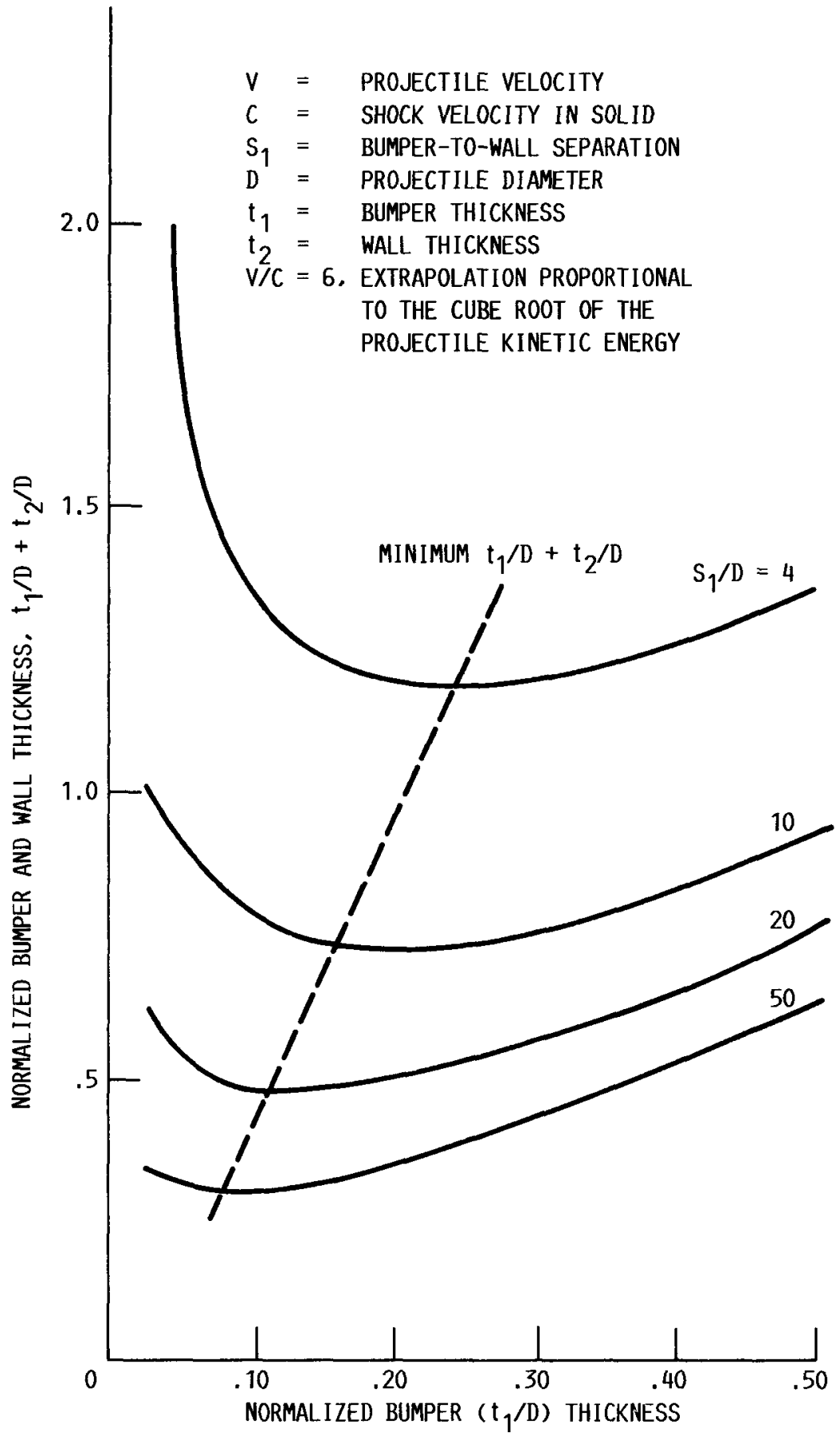

FIgURE 4. - MINIMUM WEIGHT TWO-SHEET BARRIER TO PREVENT PENETRATION. 


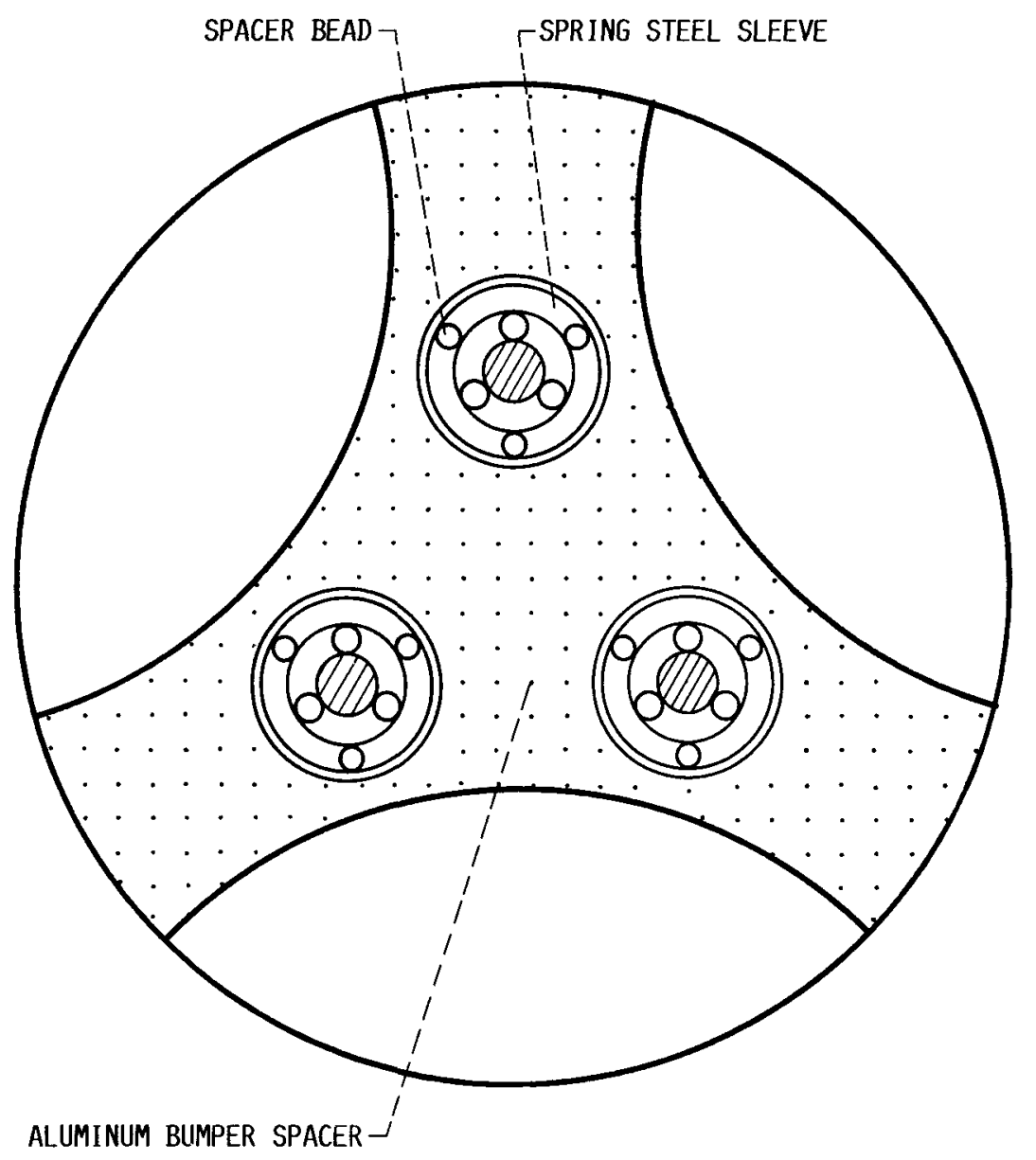

FIGURE 5. - TRANSMISSION LINE/TETHER CROSS SECTION. 
TRANSMISSION LINE LENGTH:

POWER LEVEI

PERCENT POWER LOSS ALLOWED: $1.5 \%$

VOLTAGE GRADIENT ALLOWED: $\quad 20 \mathrm{kV} / \mathrm{CM}$

RELIABILITY

METEROID SURVIVAL PROBABILITY 99.5\%

NUMBER OF YEARS $10 \mathrm{YR}$

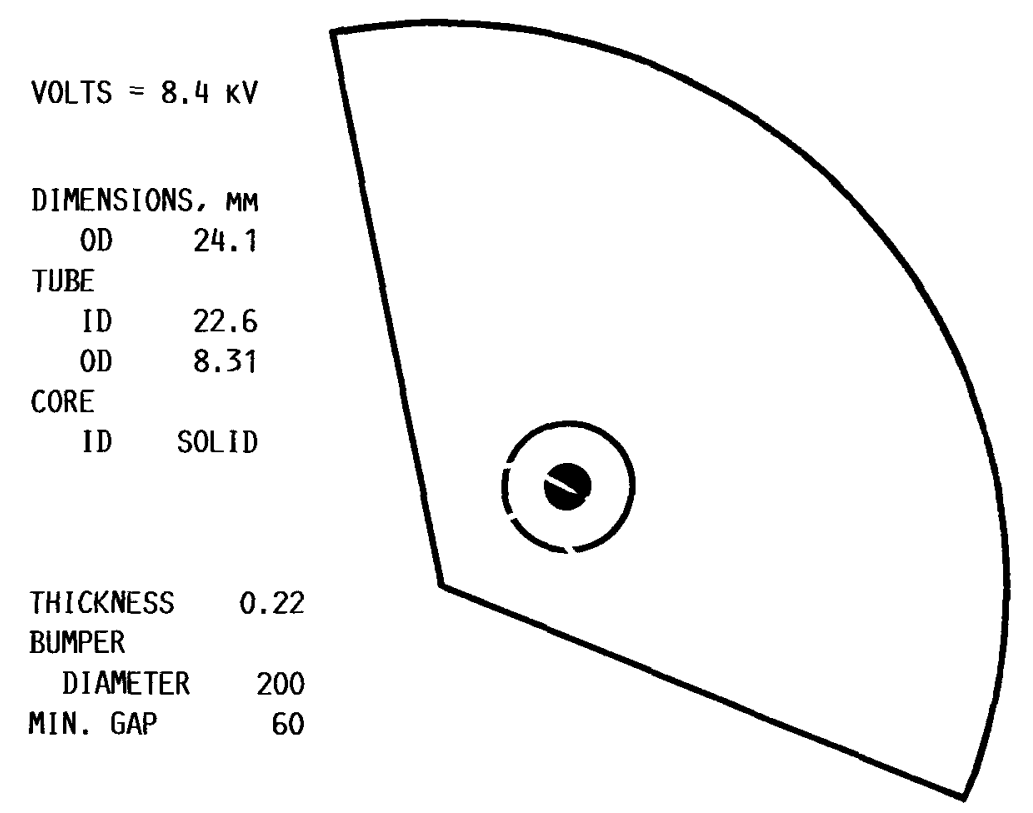

AREA AT RISK (EACH TUBE)

METEROID MASS (ARMORED AGAINST)

$758 M^{2}$

$15.3 \mathrm{MG}$

TRANSMISSION LINE MASS (TUBES AND BUMPER) $12774 \mathrm{KG}$
TRANSMISSION LINE LENGTH:

POWER LEVEL (AL

VOLTAGE GRADIENT ALLOWED:

$50 \mathrm{kV} / \mathrm{CM}$

RELIABIL ITY

METEROID SURVIVAL PROBABILITY $99.5 \%$

NUMBER OF YEARS

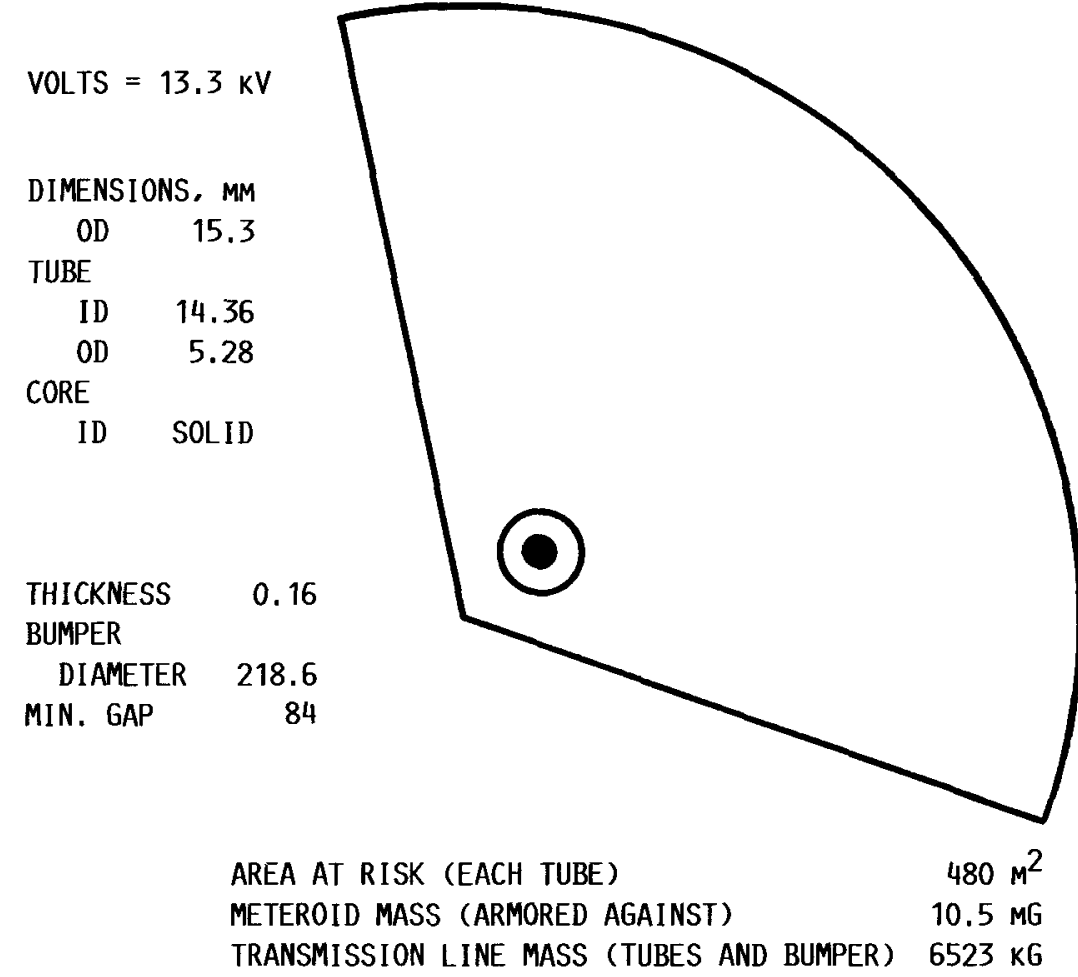

FIgURE 6. - COAXIAL TUBE ARRAY CROSS SECTIONS, $10 \mathrm{kM}$ SEPARATION DISTANCE, $V=20 \mathrm{kV} / \mathrm{CM}$ AND $50 \mathrm{kV} / \mathrm{cm}$. 
TRANSMISSION LINE LENGTH:

POWER LEVEL (ALL TUBES OPERATING)

PERCENT POWER LOSS ALLOWED:

VOLTAGE GRADIENT ALLOWED:

RELIABILITY

METEROID SURVIVAL PROBABILITY $99.5 \%$

NUMBER OF YEARS

$10 \mathrm{YR}$

\begin{tabular}{|c|c|c|}
\hline VOLTS $=$ & 7.7 & $k V$ \\
\hline DIMENSI & NS, & MM \\
\hline OD & & 8.9 \\
\hline TUBE & & \\
\hline ID & & .36 \\
\hline OD & & .08 \\
\hline CORE & & \\
\hline ID & & LID \\
\hline THICKNE & & 0.09 \\
\hline BUMPER & & \\
\hline DIAME & & 83.5 \\
\hline MIN. GA & & 27 \\
\hline
\end{tabular}

TRANSMISSION LINE LENGTH: POWER LEVEL (ALL TUBES OPERATING) 0.3 MWE PERCENT POWER LOSS ALLOWED: VOLTAGE GRADIENT ALLOWED: $50 \mathrm{kV} / \mathrm{cm}$ REL IABIL ITY
METEROID SURVIVAL PROBABILITY
$99.5 \%$

NUMBER OF YEARS

$10 \mathrm{YR}$

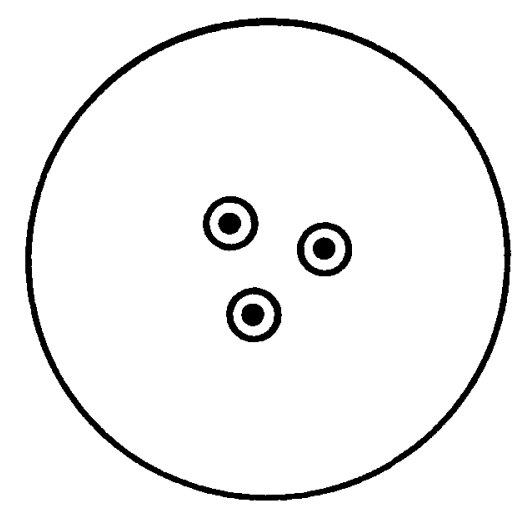

\begin{tabular}{|c|c|c|}
\hline \multicolumn{3}{|c|}{ VOLTS $=13.3 \mathrm{kV}$} \\
\hline \multicolumn{3}{|c|}{ DIMENSIONS, MM } \\
\hline OD & \multicolumn{2}{|c|}{15.3} \\
\hline \multicolumn{3}{|l|}{ TUBE } \\
\hline ID & \multicolumn{2}{|c|}{14.36} \\
\hline OD & \multicolumn{2}{|c|}{5.28} \\
\hline \multicolumn{3}{|l|}{ CORE } \\
\hline ID & \multicolumn{2}{|c|}{ SOLID } \\
\hline THICKN & & 0.16 \\
\hline \multicolumn{3}{|l|}{ BUMPER } \\
\hline DIAM & & 218.6 \\
\hline MIN. G & & 84 \\
\hline
\end{tabular}

AREA AT RISK (EACH TUBE)

$28 M^{2}$

METEROID MASS (ARMORED AGAINST)

$1.008 \mathrm{MG}$

TRANSMISSION LINE MASS (TUBES AND BUMPER) $181 \mathrm{KG}$

AREA AT RISK (EACH TUBE)

METEROID MASS (ARMORED AGAINST)

TRANSMISSION LINE MASS (TUBES AND BUMPER)
$480 \mathrm{M}^{2}$

$10.5 \mathrm{KG}$

$6523 \mathrm{KG}$

FIgURE 7. - COAXIAL TUBE ARRAY CROSS SECTIONS, $V=50 \mathrm{kV} / \mathrm{CM}$, SEPARATION DISTANCE $=1 \mathrm{kM}$ AND $10 \mathrm{kM}$. 


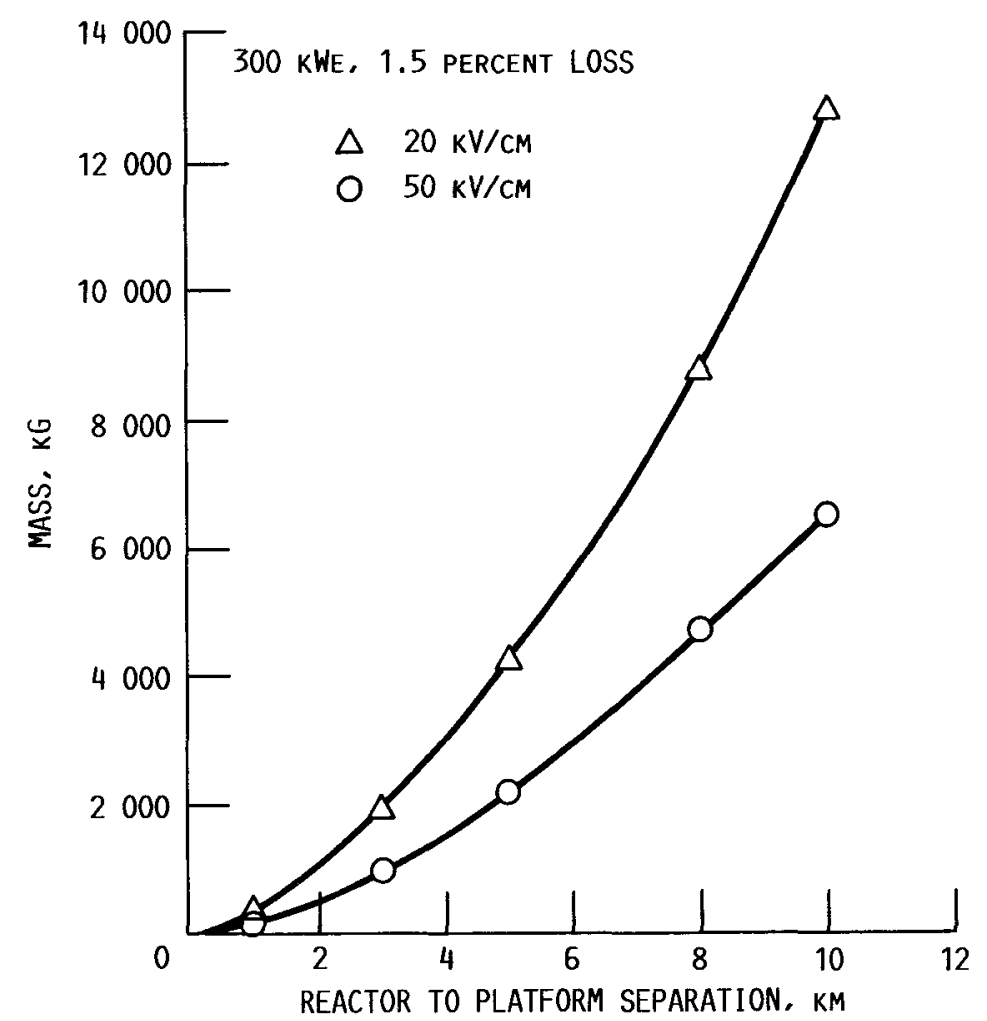

FIGURE 8. - MASS VERSUS LENGTH TRADEOFF FOR COAXIAL TUBE ARRAY. 


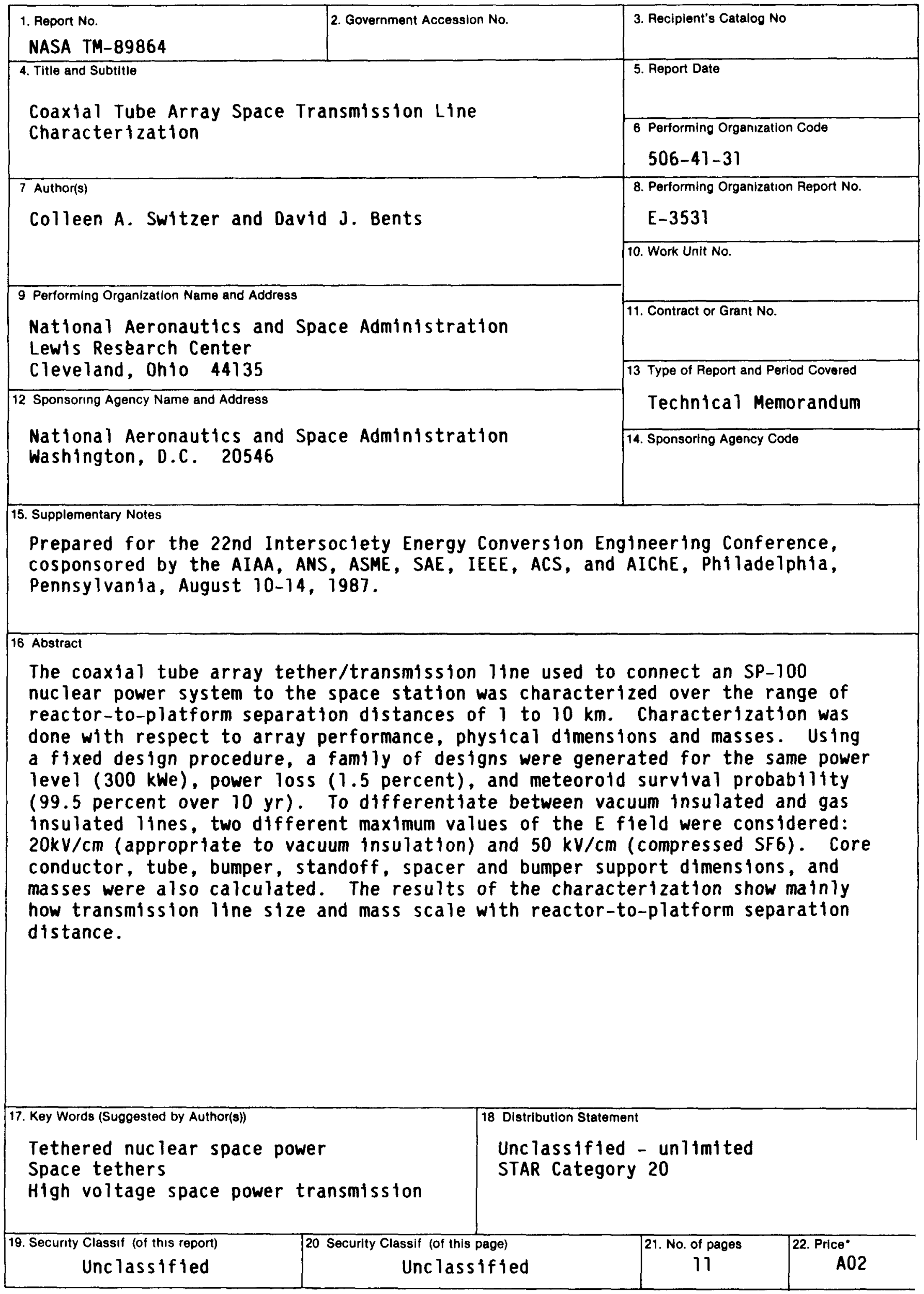

